\title{
VIOLÊNCIA DE GÊNERO: REFLEXÕES A PARTIR DO DOCUMENTÁRIO ESTAMIRA
}

\section{GENDER VIOLENCE: REFLECTIONS FROMTHE DOCUMENTARY ESTAMIRA}

\begin{abstract}
Rosane Cristina de Oliveira * rosanecrj@hotmail.com

Eliane Cristina Tenório Cavalcanti*

eliane.cavalcant@hotmail.com

* Universidade do Grade Rio, Duque de Caxias, RJ - Brasil

\section{Resumo}

O presente artigo tem como objetivo fazer uma abordagem do documentário Estamira, de Marcos Prado, com o intuito de refletir sobre o tema relações de gênero e fatores relacionados á violência doméstica e familiar. Assim, foram propostas três reflexões. Na primeira, fez-se uma breve descrição do Lixão de Jardim Gramacho, localizado no município de Duque de Caxias, local de onde Marcos Prado decidiu produzir o filme sobre a vida de Estamira. Na segunda, realizou-se uma abordagem sobre alguns aspectos da vida de Estamira que foram marcados pela violência doméstica e familiar, dentre elas: os abusos sexuais, a violência física, moral e psicológica. Ao final, serão feitas algumas considerações sobre aspectos legais sobre mulheres vítimas de violência conjugal e doméstica.
\end{abstract}

Palavras chave: Estamira, Gênero,Violência Doméstica

\section{Abstract}

The present article aims to make an approach to the documentary Estamira, by Marcos Prado, with the purpose of reflecting on the theme gender relations and factors related to domestic and family violence. Thus, three reflections were proposed. In the first, a brief description was made of the Gramacho Garden Lick, located in the municipality of Duque de Caxias, where Marcos Prado decided to produce the film about the life of Estamira. In the second, an approach was taken on some aspects of Estamira's life that were marked by domestic and family violence, among them: sexual abuse, physical, moral and psychological violence. In the end, some considerations will be made on legal aspects about women victims of marital and domestic violence.

Keywords: Estamira, Gender, Domestic Violence 


\section{INTRODUÇÃO}

"Eu quero compartilhar com vocês a minha visão do mundo, das coisas" (Estamira, 2005)

Poucos documentários podem ser tão representativos para retratar as realidades sociais contemporâneas relacionados à violência contra a mulher como Estamira. O filme de Marcos Prado ${ }^{1}$ retrata realidades sociais que fazem parte do cotidiano da periferia e das grandes cidades como a questão da violência doméstica e familiar - situação que frequentemente atravessa a experiência de dois tipos de sujeitos: os pobres e os racialmente estigmatizados. No filme, Marcos Prado conta a história de uma mulher que vive e trabalha, há mais de 20 anos, em um aterro sanitário. Estamira, a personagem principal do documentário é negra e pobre, tal como a grande maioria dos moradores de periferias e favelas.

O documentário dá a ver, faz circular sentidos sobre a violência contra a mulher difundida na sociedade brasileira. De acordo com relatos da protagonista e de seus três filhos, há a descrição de vivencias de violências sexuais sofridas desde a infância e que dizem respeito a questões de violência: doméstica e familiar, dentre elas: físicas, morais e psicológicas.

Por meio do documentário é possível perceber que Estamira viveu uma série de situações de violência em sua vida que inclusive culminaram na eclosão de problemas que podem ser analisadas sob o viés de gênero, conforme faremos ao longo deste trabalho.

A estrutura desse texto será apresentada a partir de três subtópicos. O primeiro apresenta o lócus de onde Marcos Prado decidiu fazer o filme sobre a vida de Estamira - Jardim Gramacho, um Lixão localizado no município de Duque de Caxias. No segundo, serão abordados alguns aspectos da vida de Estamira que foram marcados pela violência doméstica e familiar, dentre elas: os abusos sexuais, a violência física, moral e psicológica. Ao final, serão feitas algumas considerações sobre aspectos legais sobre mulheres vítimas de violência conjugal e doméstica.

1 Marcos Prado, antes do premiadíssimo Estamira, produziu documentários de fôlego, como Ônibus 174 (2002), e, como fotógrafo, ganhou o IX Prêmio Marc Ferrez de Fotografia (Funarte) pelo ensaio Jardim Gramacho, exatamente o lixão da Baixada Fluminense que é, há 20 anos, o posto de trabalho de Estamira, personagem título desse documentário . 


\section{O lixão de Jardim Gramacho e o encontro com Estamira}

O depósito de lixo, pelo menos desde a década de 60, é uma presença persistente nas imagens do cinema brasileiro. Filmes como Um Favelado (Marcos de Farias, 1962), reunido no filme Cinco Vezes Favela (1962), passando por Ilha das Flores (Jorge Furtado, 1989), Boca de Lixo (Eduardo Coutinho, 1992); Lixo Extraordinário, dirigido (Lucy Walker, 2009) e Estamira (Marcos Prado, 2005).

Em 1994, preocupado com problemas ecológicos, Marcos Prado passou a freqüentar um Lixão localizado no o Jardim Gramacho, no município de Duque de Caxias, para onde eram levados $85 \%$ do lixo produzido no Rio de Janeiro, segunda maior metrópole do Brasil. O Lixão Jardim Gramacho (mais tarde, Aterro Sanitário), possuía um espaço de mais de um milhão e trezentos metros quadrados, eram depositados, há mais de 25 anos (BASTOS, 2012). Na época da realização e lançamento do filme, o Aterro era considerado o maior da América Latina e recebia cerca de oito mil toneladas de lixo por dia.

O Lixão estava instalado em um terreno argiloso, cercado de mangues, às margens da Baía de Guanabara. Próximo ao Aterro Metropolitano de Jardim Gramacho desaguam os rios Iguaçú e Sarapuí, que cortam cinco municípios mais populosos do Estado: Nova Iguaçu, Mesquita, Nilópolis, Belford Roxo, São João de Meriti e Duque de Caxias (RIBEIRO, 2011).

Considerado um dos maiores depósitos de lixo a céu aberto do mundo, ele recebia aproximadamente 17 mil toneladas de resíduos sólidos por dia, sendo que somente da cidade do Rio de Janeiro vinha mais da metade - 9 mil toneladas. Além dos problemas de contaminação do solo e de poluição atmosférica, a presença do lixão nesse local da Baixada Fluminense também era tida uma ameaça ambiental pela sua proximidade à Baía de Guanabara. (BASTOS, 2012).

O referido lixão se mantinha em operação desde os meados da década de 1970 mas, apesar dessa atividade efetivamente insalubre, penosa e perigosa existir por todos esses anos e manter a efetiva presença dos catadores e catadoras no garimpo do lixo. O processo de fechamento do Aterro Metropolitano de Jardim Gramacho foi adiantado para junho de 2012, resultado de compromissos políticos e ambientais assumidos para a preparação da Conferência das Nações Unidas (Rio+20). Inicialmente, a alegação técnica foi de que havia um esgotamento dos espaços para acomodação dos materiais orgânicos e inorgânicos, em função da iminência de risco ambiental (BASTOS, 2012).

O fotógrafo e cineasta Marcos Prado, decidiu conhecer de perto o local em que, segundo ele, "era diariamente depositado o lixo produzido em casa" (PRADO, 2004, p. 9). Marcos Prado passou 
registrar o cotidiano do Lixão de Jardim Gramacho - um lugar repulsivo à primeira vista, tomado por sujeira, montes de detritos, urubus e catadores que encontram no lixão uma forma de subsistência. Foram estes últimos que atraíram a atenção do diretor, que, inicialmente, pensou em desenvolver um estudo fotográfico sobre aquelas pessoas,

Em meio ao ambiente insalubre que o rodeava, ele encontra uma senhora, com roupas e postura peculiares, contemplando a paisagem do lixão. Prado (2004, p.9) descreve o seu encontro assim:

[...] esbarrei-me com uma senhora sentada em seu acampamento, contemplando a paisagem de Gramacho. Aproximei-me dela e pedi-lhe para tirar o seu retrato. Ela me olhou nos olhos consentindo e disse para me sentar ao seu lado. Conversamos por um longo tempo. Estamira era seu nome. Contou que morava num castelo todo enfeitado com objetos encontrados no lixo e que tinha uma missão na vida: revelar e cobrar a verdade. Nos tornamos amigos. Um dia, tempos depois de conhecê-la, ela me perguntou se eu sabia qual era a minha missão. Antes que eu respondesse, Estamira disse: "a sua missão é revelar a minha missão". Decidi fazer um documentário sobre a vida dela.

A catadora Estamira ${ }^{2}$ era apenas mais uma das várias mulheres que catavam dejetos naquele lugar. Ao permitir que o fotógrafo lhe fizesse um retrato, ela o chamou para conversar. Marcos se encanta com o discurso daquela senhora, Eles se tornam amigos e, certo dia, ela the pergunta qual seria sua missão. Antes que ele pudesse responder, ela diz que a missão dele era a de revelar a verdade dela. Desta forma, Marcos Prado decide fazer um filme sobre sua vida e nomeia a produção com o nome da senhora: Estamira (PRADO, 2004).

\section{Retratos da violência}

A história de Estamira é marcada por violência doméstica e familiar, abusos sexuais, dentre eles: os estupros, as traições vivenciadas em seus dois casamentos, o distanciamento de sua filha mais nova, a dependência alcoólica e o fato de ter sido moradora de rua. Estamira é levada à força à prostituição por

2 Estamira Gomes de Sousa foi catadora do Aterro Metropolitano de Jardim Gramacho, o maior lixão a céu aberto da América Latina, na Baixada Fluminense, na cidade do Rio de Janeiro, e morreu, aos 70 anos, em 2011 em decorrência de uma septicemia - infecção generalizada - no Hopital Miguel Couto, na Gávea, Rio de Janeiro. 
seu avô quando tinha 12 anos, neste momento, outro fator importante começa a emergir, que é a relação de como conseguir dinheiro, relação esta, estabelecida pelo avô e que ressurge no momento em que ela é levada à prostituição. Tais fatores podem ser relacionados, futuramente, com a dependência econômica de um marido que a maltratava, e com a escolha do lixão como forma de se manter. Ao sair da prostituição, acaba em um casamento infeliz marcado pela violência moral, psicológica, pela dependência econômica de um outro que é o opressor, pela humilhação, machismo, racismo e adultério.

Depois desse casamento ela passou a desenvolver sintomas psicóticos sendo diagnosticada como doente mental. A própria filha de Estamira afirma no documentário que a mãe passou a ser acometida pelas primeiras crises de loucura após a mesma ser violentada e agredida pelo próprio marido (PRADO, 2004).

Saffioti (1999) e Diniz (2006) esclarecem que a violência doméstica refere-se a situações de violência que ocorrem dentro do espaço doméstico, envolvendo pessoas que tem laços de consanguinidade, como por exemplo, pais e filhos, avós e netos e também entre pessoas que não tem esse tipo de relação como patrão e empregada. Sendo que as mulheres e as crianças são as maiores vítimas. Para Chauí (1980, p.60), a violência constitui-se “como um conjunto de mecanismos visíveis e invisíveis que vem do alto para baixo da sociedade, unificando-a verticalmente e espalhando-se pelo interior das relações sociais".

Saffioti e Almeida (1995) afirmam que após o desenvolvimento de estudos de gênero ${ }^{3}$, vários autores passaram a utilizar a partir de 1990, violência de gênero ${ }^{4}$ como um conceito ampliado de violência contra a mulher. Scott (2006) esclarece que a violência de gênero refere-se ao fenômeno da violência entendida de forma mais ampla. Gênero diz respeito à construção sócio-histórica do ser homem e do ser mulher que dita normas e valores que organizam tanto as relações entre homens e

3 Segundo Saffiotti (1995), gênero refere-se a um conjunto de condutas e normas modeladoras dos seres humanos em homem e em mulher e relaciona-se ao desempenho de papéis e responsabilidades culturalmente atribuídos ao sexo antes mesmo do nascimento. A autora destaca que a "violência de gênero" é uma expressão introduzida pelo movimento feminista para atribuir nome as agressões masculinas praticadas contra a população feminina, apesar do termo não ser sinônimo, necessariamente, de violência entre homens e mulheres.

4 De acordo com Araújo (2013), o conceito de gênero abrange não apenas as mulheres, mas crianças e adolescentes, que no Brasil são objetos da violência masculina, constituindo assim as relações de gênero. Tal conceito também pode ser utilizado para definir a violência conjugal, pois engloba várias formas de violência que envolvem as relações de gênero e poder. Entretanto, podemos dizer que a violência contra a mulher é uma das principais formas de violência de gênero. 
mulheres. Assim, toda a forma de violência que acontece no contexto dessas relações constitui uma violência de gênero.

Diniz (2006) explica que o uso da expressão violência contra a mulher se deve ao fato de que aproximadamente dois terços das vítimas de violência doméstica são mulheres. Na esteira desta constatação o autor cita as principais formas de violência contra mulher evidenciadas em pesquisas.

Violência física, sexual e psicológica que ocorre nas famílias, como, por exemplo: o abuso sexual de meninas; o estupro conjugal; a mutilação genital feminina e outras práticas tradicionais que causam danos às mulheres; e toda a forma de exploração contra a mulher. Violência sexual e psicológica que acontece no seio da comunidade, tais como: estupro e outras formas de violação e abuso sexual e outras formas de intimidação no ambiente de trabalho, nas instituições de ensino ou em qualquer outro lugar; tráfico de mulheres e a prostituição forçada. Violência sexual e psicológica perpetrada e endossada pelo Estado, onde quer que ela ocorra. Cabe mencionar aqui as violações de mulheres em conflitos armados; as situações de escravidão sexual; de gravidez, esterilização ou aborto forçado; uso coercitivo de métodos contraceptivos e de seleção pré-natal de sexo. (DINIZ, 2006, p. 236).

No caso de Estamira, é possível observamos que no decorrer de sua vida a violência foi uma constante. Sofreu violência física, sexual e psicológica desde a infância. Diniz (2006) ressalta que a violência de gênero afeta a população feminina durante todas as fases do seu ciclo vital, independente da cultura, raça, crença religiosa, grupo étnico, no entanto a violência é exacerbada pelas condições socioeconômicas e pela dificuldade de acesso a bens e serviços, o que pode se aplicar a contento ao caso de Estamira.

Diniz (2006) menciona também que mulheres vítimas de violência tem maior propensão a receberem diagnósticos psiquiátricos. Muitas não são nem sequer capazes de nomear suas vivências como violentas e tendem a se sujeitar a um tipo de violência para evitar outros. As consequências biopsicossociais são difíceis de mensurar, embora afetem a maioria das vítimas e suas famílias. A violência contra a mulher produz efeitos intensos e devastadores, muitas vezes irreparáveis, na esfera emocional. Oliveira $(2005$, p.3) refere que "as mulheres vítimas de violência têm queixas, distúrbios e patologias, físicas e mentais, e utilizam os serviços de saúde com maior frequência do que aquelas sem esta experiência". 
Durante a sua vida Estamira foi tida oficialmente como portadora de distúrbios mentais ${ }^{5}$ sendo internada, psiquiatrizada, farmacologizada. A protagonista foi vítima de uma construção cultural que tem legitimado a violência, a violação e o assenhoramento dos corpos das mulheres, que tem legitimado o heterossexismo e o estupro, que tem perpetuado as desigualdades sociais, o racismo e a degradação humana.

No Documentário, é possível perceber as diversas críticas que Estamira faz sobre esses problemas: "Não gosto de erros, não gosto de suspeitas, não gosto de judiação, de perversidade, não gosto de humilhação, não gosto de imoralidade" (ESTAMIRA, 2005).

\section{O impacto da violência doméstica - Medidas políticas e legais}

Situações de pobreza e exclusão social como a de Estamira estão intimamente ligadas à existência da violência doméstica, principalmente contra a mulher. De acordo com Dias (2006) a violência doméstica pode ser definida como qualquer tipo de abuso físico, sexual ou emocional praticado por um parceiro contra o outro ou ainda contra crianças e/ou idosos, no ambiente doméstico. Apesar de a violência doméstica ser um fenômeno antigo e persistente, somente passou a fazer parte das estatísticas nacionais no final do século XX.

A discussão sobre a violência doméstica só se inseriu na agenda pública na década de 80 , se concretizando a partir de 1990 (SILVA, 2010). Vários autores afirmam que a violência doméstica está sendo considerada um problema de saúde pública no país, por causa das sérias consequências que ela ocasiona à saúde, assim como para o desenvolvimento psicológico e até de mesmo social de indivíduos e grupos (SCHRAIBER, 2013; KRUNG et al., 2002). Dados de delegacias de mulheres espalhados por todo Brasil apontam que cerca de $70 \%$ das denúncias são de mulheres que sofreram agressão no âmbito doméstico (SCHRAIBER, 2000). Nesse sentido, Silva (2013) ainda aponta que a violência é considerada um dos grandes problemas sociais e políticos, bem como um agravo para os problemas nas relações humanas.

$5 \quad$ Em um trecho do documentário, Estamira mostra um papel no qual consta o diagnóstico de um psiquiatra, alegando que ela é "portadora de quadro psicótico de evolução crônica e alucinações auditivas" (Estamira, 2005). 
Para Dias (2006.), situações de pobreza e exclusão social estão intimamente ligadas à existência da violência doméstica. Kronbauer e Meneghel (2005) destacam que a pobreza familiar e o baixo nível masculino de instrução predizem os maus tratos físicos à mulher. Entre os fatores associados ao risco de violência doméstica contra as mulheres incluem-se os baixos salários e as pressões econômicas. Além disso, os homens desempregados são mais violentos com suas esposas e filhos. Dessa forma, os sinais de exclusão social estão associados a maiores prevalências das agressões.

A violência de homens contra as mulheres pode ser interpretada como fruto de uma cultura de dominação masculina. As diversas formas de discriminação e de violência contra as mulheres são manifestações de relações de poder historicamente desiguais. Denominadas violência de gênero, são também violação dos direitos das mulheres. Reconhecidos como parte integral dos direitos humanos pela Conferência Mundial dos Direitos Humanos, da Organização das Nações Unidas (ONU), os direitos humanos das mulheres e das meninas foram, em 1993, pela primeira vez, expressamente concebidos como parte integrante e indivisível dos direitos humanos universais. A violência de gênero - que tem no componente cultural seu grande sustentáculo, fator de produção e de reprodução de violações contra as mulheres - versa no texto da Declaração como incompatível com a dignidade e o valor da pessoa humana (SAFFIOTI, 2001).

No Brasil, várias políticas públicas voltadas para a proteção da mulher foram implantadas principalmente a partir da Constituição de 1988, considerada um divisor de águas que inaugurou um sistema baseado em valores universais de igualdade e que trouxe em seu texto um conjunto de ações e garantias afirmativas para a promoção dos direitos das mulheres. Além dela, pode-se citar a Organização Mundial de Saúde (OMS) que, em 1994, definiu oficialmente a violência contra a mulher como: "todo ato que produz dano físico, sexual ou psicológico a mulher, incluindo as conseqüências desses atos, a coerção, privação arbitrária da liberdade, independente se ocorre na instância pública ou privada" (MINISTÉRIO DA SAÚDE, 2001, p. 19).

Também é importante citar nessa trajetória a Lei n 10.778/03 de 2004, que passa a considerar a notificação dos casos de violência contra a mulher no Sistema Único de Saúde, fato que permitiu dimensionar a amplitude do problema, podendo, a partir daí, caracterizar as circunstâncias da violência, o perfil das vítimas e dos agressores, contribuindo para o desenvolvimento de políticas e atuações governamentais para enfrentamento da violência. A principal mudança é a inserção da notificação compulsória, pela qual todos os atos de violência passaram a ser notificados em delegacias (ALMEIDA; COSTA, 2002). 
Vale ressaltar aqui a Lei Maria da Penha ${ }^{6} n^{\circ} 11.340$ foi promulgada em agosto de 2006. Nela, está disposto "o aumento do rigor nas punições contra agressões sofridas pelas mulheres no âmbito doméstico ou familiar" (SILVA, 2010, p. 566). A Lei prevê a condenação do agressor, não havendo mais a possibilidade de conciliação entre os envolvidos. Desse modo, este conflito é matéria criminal, sendo responsabilidade do sistema penal tradicional. Além disso, ela requer maior participação das mulheres nos espaços de poder e decisão como forma de garantir seus direitos e políticas públicas voltadas para melhor atendê-las.

Nesse contexto, Amaral et al. (2001) afirmam que, no Brasil, estima-se que, a cada quatro minutos, uma mulher seja agredida, sendo que em $85,5 \%$ dos casos de violência contra mulheres, os agressores são seus parceiros. De acordo com Macedo (2011), para que a Lei Maria da Penha tenha efetividade, é necessária uma mudança no seio da sociedade, pois a cultura da violência está no coletivo. Apesar do crescente reconhecimento deste conflito como problemática social, a violência de gênero contra a mulher é ainda naturalizada, sendo uma expressão da sociedade patriarcal na qual estamos inseridos. Nesta sociedade existe uma tolerância de que os homens podem exercer sua virilidade baseada na força e dominação, que caracterizam o gênero masculino (SAFFIOTI, 2001).

Ao tratar da violência no âmbito privado, conhecida como violência doméstica, em que os agressores são geralmente parentes ou pessoas próximas do convívio familiar, há o reconhecimento de que a violação dos direitos humanos, mesmo acontecendo no âmbito da família ou da unidade doméstica, diz respeito à sociedade e ao poder público (ALMEIDA, 2007).

\section{Considerações finais}

A partir do documentário Estamira procuramos fazer algumas reflexões sobre o tema relações de gênero e fatores relacionados á violência doméstica e familiar. A história de Estamira é marcada por abusos sexuais, dentre eles: os estupros e traições vivenciadas em seus dois casamentos. No

\footnotetext{
6 Com o objetivo de por fim à violência de gênero considerada atualmente a mais preocupante questão socio-cultural, a Lei ${ }^{\circ}$ 11.340/2006, denominada Lei Maria da Penha, sancionada em 7 de Agosto de 2006 pelo presidente Lula, e publicada no DOU no dia 8 de agosto de 2006, cria mecanismos para coibir a violência doméstica e familiar contra a mulher, nos termos do $\S 8^{\circ}$ do art. 226 da CF/88, da Convenção sobre a eliminação de todas as formas de discriminação contra as mulheres e da Convenção Interamericana para Prevenir, Punir e Erradicar a Violência contar a Mulher e ainda dispõe sobre a criação dos Juizados de Violência Doméstica e Familiar contra a Mulher e altera o Código de Processo Penal, o Código Penal e a Lei de Execução Penal (DIAS, 2007).
} 
documentário, de acordo com relatos da protagonista e de seus três filhos, há a descrição de vivencias de violências sexuais, físicas, morais e sociais, sofridas desde a infância e que dizem respeito a questões de gênero.

O documentário também apresenta uma mulher negra, pobre, catadora do Lixão de Jardim Gramacho, diagnosticada como esquizofrênica pelos médicos em função da violência sofrida durante os seus dois casamentos. O filme representa uma expressão da desigualdade de gênero que na grande maioria, ocorre no âmbito da vida doméstica e tem como principal autor o seu parceiro íntimo.

O que se percebe pela narrativa, é que Estamira, antes de sofrer as violências que foram retratadas neste artigo, não apresentava qualquer quadro clínico anterior a este momento de sua vida, o que levanta um questionamento importante: Será que se Estamira tivesse vivido outra realidade, o desfecho de sua vida teria sido diferente?

Estamira faz parte do contingente de mulheres que são sistematicamente agredidas, em geral, por seus parceiros. A cultura de submissão das mulheres em relação aos homens continua presente na atual sociedade e favorece, em grande medida, os índices do fenômeno de violência doméstica, violência essa que precisa ainda ser enfrentada a partir de suas causas e consequências pela sociedade como um todo.

\section{Referências}

ALMEIDA, Suely S. de. Essa violência mal-dita. In: Almeida, Suely $S$. de. (org.). Violência de gênero e políticas públicas. Rio de Janeiro: Ed. UFRJ, 2007, p. 23-41.

ALMEIDA, M. G.; COSTA, N. F. P. Protocolo de assistência à saúde sexual e reprodutiva para mulheres em situação de violência de gênero. 2 . ed. rev. Rio de Janeiro: BEMFAM, 2002. Disponível em:. Acesso em: dez. 2012.

AMARAL, C. C. G.; GUIMARÃES, R. P. A.; ANDRADE NETA, R. N.; FROTA, C. R. Antes do tapa na cara. In: Anais do XVI Congresso Brasileiro de Economia Doméstica e IV Encontro Latino Americano de Economia Doméstica. Viçosa, MG, 2001

ARAÚJO, M. F. Gênero e violência contra a mulher: perigoso jogo de poder e dominação. Universidade Estadual Paulista (UNESP). Assis - São Paulo - (Brasil). Revista Eletrônica Internacional de La
Union Latinoamericana de Entidades de Psicologia, 2013.

BASTOS, Valéria Pereira. Jardim Gramacho e os catadores de materiais recicláveis: território extraordinário do lixo. Rio de Janeiro, 2012.

CHAUI, M. A não-violência do brasileiro: um mito interessantíssimo. Almanaque: Cadernos de Literatura e Ensaio. Brasiliense, n. 11, 1980.

CUNHA, Rogério Sanches; PINTO, Ronaldo Batista.

Violência Doméstica: lei Maria da Penha comentada artigo por artigo. São Paulo: Editora Revista dos Tribunais, 2007.

DIAS, Maria Berenice. A Lei Maria da Penha na justiça: a efetividade da Lei $n .^{\circ} 11.340 / 06$ de combate à violência doméstica e familiar contra a mulher. São Paulo: Revista dos Tribunais, 2007. 
DINIZ, Glaucia. Violência, exclusão social e desenvolvimento humano. Estudos em representações sociais. Brasília: Ed. UnB, 2006.

KRONBAUER, J.; MENEGHEL, S. Perfil da violência de gênero perpetrada por companheiro. Revista de Saúde Pública, 39(5), 695-701, (2005).

KRUNG, E. G. et al. Relatório mundial sobre violência e saúde. Organização Mundial da Saúde, Genebra, 2002. Disponível em:. Acesso em: dez. 2012.

MACEDO, P. J. 0 psicólogo brasileiro no sUS: quantos somos e onde estamos? Psicologia em Estudo, Maringá, v. 16, n. 3, p. 479-489, jul./set. 2011.

OLIVEIRA. C. Práticas dos profissionais de saúde da família voltadas para mulheres em situação de violência sexual:uma abordagem de gênero [tese]. São Paulo: Universidade de São Paulo, Escola de Enfermagem, 2005.

PRADO, Marcos. Jardim Gramacho. Rio de Janeiro: Argumento, 2004.

Estamira. [Filme-vídeo]. Produção de James D’Arcy, José Padilha, Marcos Prado, direção de Marcos Prado. Rio de Janeiro. 2005.

RIBEIRO, Ricardo Laino. O Impacto do Encerramento do Aterro Metropolitano de Jardim Gramacho (AMJG) sob a Ótica dos Comerciantes do Setor Informal de Alimentos. Rio de Janeiro, 2011.

SAFFIOTI, H. F. Já se mete a colher em briga de marido e mulher, São Paulo em Perspectiva, v. 13, n.4, p. 82-91, 1999.

Contribuições feministas para o estudo da violência de gênero. Em L. Q. Moraes, e R. Naves (Orgs.).Advocacia pro bono em defesa da mulher vítima de violência. Campinas, SP: Unicamp, pp. 197-220, 2002.

Gênero, patriarcado e violência. São Paulo: Perseu Abramo, 2001.
SAFFIOTI, H; ALMEIDA S. Violência de gênero poder e impotência. Rio de Janeiro, Livraria e Editora Revinter Ltda., 1995.

SCHARAIBER, L. B. A violência contra mulheres: demandas espontâneas e busca ativa em unidade básica de saúde. Saúde e Sociedade, v. 9, n. 1/2, p. 3-15, 2000. Disponível em: . Acesso em: jan. 2013.

SCOTT, Joan W. Gênero: uma categoria útil de análise histórica. Educação \& Realidade. Porto Alegre, v. 20, n. 2, p. 71-99, jul./dez. 1995.

SILVA, S. G. Preconceito e discriminação: as bases da violência contra a mulher. Revista Psicologia Ciência e Profissão, Brasília, v. 30, n. 3, p. 556-571, 2010. Disponível em: . Acesso em: jul. 2013. 
Recebido em: 22/10/2017

Aceito em: 12/11/2017

Endereço para correspondência:

(c) (i)

Nome: Rosane Cristina de Oliveira

Esta obra está licenciada sob uma Licença Creative

Email: rosanecrj@hotmail.com

Commons Attribution 3.0 